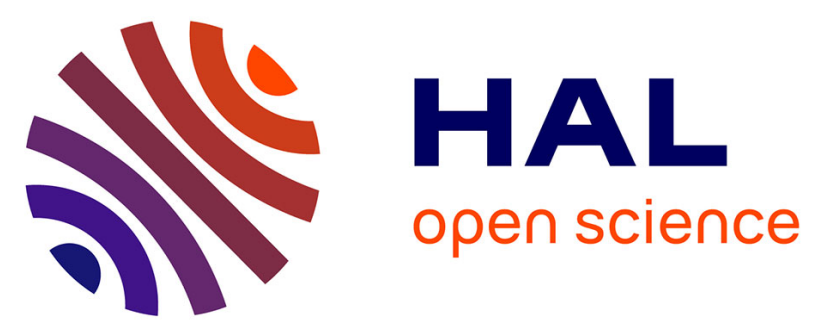

\title{
Therapeutic drug monitoring as a tool to optimize 5-FU-based chemotherapy in gastrointestinal cancer patients older than 75 years
}

Pauline Macaire, Katarzyna Morawska, Julie Vincent, Valérie Quipourt, Sophie Marilier, François Ghiringhelli, Leila Bengrine-Lefevre, Antonin Schmitt

\section{To cite this version:}

Pauline Macaire, Katarzyna Morawska, Julie Vincent, Valérie Quipourt, Sophie Marilier, et al.. Therapeutic drug monitoring as a tool to optimize 5-FU-based chemotherapy in gastrointestinal cancer patients older than 75 years. European Journal of Cancer, 2019, 111, pp.116 - 125. 10.1016/j.ejca.2019.01.102 . hal-03486193

\section{HAL Id: hal-03486193 https://hal.science/hal-03486193}

Submitted on 20 Dec 2021

HAL is a multi-disciplinary open access archive for the deposit and dissemination of scientific research documents, whether they are published or not. The documents may come from teaching and research institutions in France or abroad, or from public or private research centers.
L'archive ouverte pluridisciplinaire HAL, est destinée au dépôt et à la diffusion de documents scientifiques de niveau recherche, publiés ou non, émanant des établissements d'enseignement et de recherche français ou étrangers, des laboratoires publics ou privés.

\section{(ㄷ)(1) $\$$}

Distributed under a Creative Commons Attribution - NonCommerciall 4.0 International 


\section{Therapeutic Drug Monitoring as a tool to optimize 5-FU based}

2

3

4 Pauline Macaire ${ }^{a, b}$, Katarzyna Morawska ${ }^{a}$, Julie Vincent ${ }^{c}$, Valérie Quipourt ${ }^{d}$, Sophie Marilier ${ }^{d}$, François

5 Ghiringhellib, ${ }^{b, c}$, Leila Bengrine-Lefevre ${ }^{c}$ and Antonin Schmitt ${ }^{a, b}$

6

7

8

9

10

\section{than 75 years}

Affiliations:

a. Pharmacy Department, Centre Georges-François Leclerc, 1 rue Pr. Marion, 21000 Dijon, France

b. INSERM U1231, University of Burgundy Franche-Comté, 7 Bd Jeanne d'Arc, 21000 Dijon, France

c. Medical Oncology Deparment, Centre Georges-François Leclerc, 1 rue Pr. Marion, 21000 Dijon, France

d. Department of Geriatrics and Internal Medicine, Hospital of Champmaillot, University Hospital, 21079 Dijon, France; Geriatric Oncology Coordination Unit in Burgundy, University Hospital, 21079 Dijon, France.

Corresponding author address:

Antonin Schmitt, Centre Georges-François Leclerc, Service Pharmacie, 1 rue Pr. Marion, 21000 Dijon. aschmitt@cgfl.fr

Keywords: elderly, 5-fluorouracil, gastrointestinal cancer, therapeutic drug monitoring 


\section{ABSTRACT:}

\section{Aims}

Most clinical trials exclude elderly people, leading to a limited understanding of the benefit/risk ratio in this population. In despite existing data regarding the oncological management of elderly receiving 5-FU-based regimen, our objective was to investigate 5-FU exposure/toxicity relationship in patients $\geq 75$ years and compare the effectiveness of 5-FU Therapeutic Drug Monitoring between elderly and younger patients.

Methods

154 patients (31 of whom are over 75) with gastrointestinal cancers, who were to receive 5FU-based regimens were included in our study. At cycle 1, the 5-FU dose was calculated using patient's Body Surface Area, then a blood sample was drawn to measure 5-FU concentration and 5-FU dose was adjusted at the subsequent cycles based on cycle 1 concentration. Assessments of toxicity was performed at the beginning of every cycle.

\section{Results}

$71 \%$ of elderly patients required dose adjustments after cycle 1 , compared to $50 \%$ for younger. Percentage of patients within 5-FU AUC range at cycle 2 was $64 \%$ and $68 \%$ for respectively elderly and younger patients. The proportion of elderly patients experiencing severe toxicities felt from $15 \%$ at cycle 1 to only $5 \%$ at cycle 3 .

\section{Conclusion}

PK-guided 5-FU dosing algorithm, leading to an improved tolerability while remaining within therapeutic concentration range, is even more valuable for patients over 75 years old than in younger. 


\section{BACKGROUND}

Since its original synthesis in the late 1950s, fluorouracil (5-FU) continues to be widely used in the treatment of many cancers, including oesophagus, stomach, pancreas and colorectal cancer (CRC) both as adjuvant therapy of early stage or in advanced setting $(1,2)$. Over the last decades, knowledge improvement in 5-FU pharmacokinetics (PK) and mechanism of action led to development of new treatments, based on the addition of the biomodulating agent folinic acid, association with other cytotoxic drugs, or modification of 5-FU administration schedule. Originally, 5-FU alone was delivered as a bolus. Nowadays, administration by continuous intravenous infusion is used. Indeed, it was shown that this delivery method increased 5-FU exposure duration, leading to an improved cytotoxic activity and clinical effectiveness, while limiting toxicity (3-5). Despite these therapeutic progresses, 5-FU is often the source of severe treatment-related toxicities requiring hospitalization and leading to death in $0.5 \%$ to $2 \%$ of cases $(6-8)$.

The most well-known biochemical cause of intolerance to fluoropyrimidines is deficiency of dihydropyrimidine dehydrogenase (DPD) $(9,10)$. DPD is defined as the first and rate-limiting enzyme in the catabolic pathway of 5-FU, responsible for more than $80 \%$ of 5-FU elimination $(11,12)$. Partial or complete deficiency in the DPD enzyme has been observed in $3-5 \%$ and $0.1 \%$ of the general population, respectively (13-15). DPD deficient patients experience excessive and severe toxicity in the form of neutropenia, diarrhoea, mucositis and hand-foot syndrome. Overall, DPD deficiency is observed in $39-61 \%$ of patients developing severe toxicity $(8,16)$. In all patients, DPD deficiency is confirmed by sequence analysis of DPYD, the gene encoding DPD, used as predictor of fluoropyrimidines-related toxicity when a pathological mutation is found. To date, more than 30 sequence variations in the DPD gene 
have been identified, with the most well-established variant being $D Y P D^{*} 2 A(17,18)$. To improve efficacy and reduce toxicity, previous investigations focused on the relationship between 5-FU plasma concentration and DPD activity to determine individual dose adjustment in patients presenting DPD gene mutation (19-22). However, 5-FU pharmacokinetic variability is affected by many others factors such as sex, disease status, nutritional condition, organ function, co-medication, explaining frequent over and underexposure even though 5-FU dosage adjustment by DYPD genotype.

5-FU dosing is traditionally calculated according to Body Surface Area (BSA). Recent data confirm the lack of scientific rational for 5-FU BSA-based dosing (23). As previously demonstrated, there is no potential correlation between BSA and 5-FU plasma clearance (24), possibly explaining the large 5-FU interindividual concentrations variation in patients treated with standard schedule based on BSA. Because 5-FU is characterized by a strong toxicity-exposure relationship and a narrow therapeutic window, the use of therapeutic drug monitoring (TDM) approaches are greatly supported $(25,26)$. Some studies have demonstrated successful strategies to monitor 5-FU blood concentrations and adjust individual doses based on systemic exposure (27-30). Area Under the Curve (AUC) of 5-FU concentrations is considered to be the most relevant pharmacokinetic parameter associated to 5-FU-related efficacy and toxicity. Because of its intrinsic variability, it is generally considered that an AUC range of $20-30 \mathrm{mg} . \mathrm{h} / \mathrm{L}$ is required for successful therapy $(31,32)$. In our centre, we have chosen to use an algorithm based on Gamelin's paper (29). Due to the precision of 5 -FU measurements, a small dose modification (i.e., $\pm 5 \%$ ) would not have a clinical or biological incidence, we extended the Gamelin's range of target AUC to 18-28 mg.h/L, to start dose adjustment at $\pm 10 \%$. 
Currently, $60 \%$ of malignant disease occurs in persons over 65 years and more than half of these patients are over 70 years old. However, most clinical trials exclude elderly people by design. Consequently, limited data are available to explore the risks and benefits of specific cancer-treatment regimens in this population. Commonly, chemotherapy doses are empirically reduced in elderly patients, mainly to prevent serious side effects. In therapeutic trials and randomized studies, 5-FU adjuvant monotherapy has shown comparable benefits and similar toxicity rates for patients aged 65 and over as for younger one's $(33,34)$. Nevertheless, this knowledge is based on clinical trials which, by definition, select patients less likely to have comorbidities or functional impairments when compared to the general elder population.

To date, no initial 5-FU dose reduction is recommended for elderly patients but, in clinical practice, empirical dose reductions or shorter chemotherapy regimens are often prescribed in elderly patients because of the hypothetical risk of toxicity. Thus, the main objective of the present study is to investigate exposure/toxicity relationship of 5-FU-based regimens in individuals aged $\geq 75$ years old. The secondary objective of this work is to compare the effectiveness of 5-FU TDM between elderly and younger patients.

\section{Patients \& Methods}

\section{Population}

This retrospective analysis was carried out in a database covering all patients diagnosed with gastrointestinal cancer who received a 46h continuous 5-FU infusion from April 2014 to February 2016 in the Dijon's Cancer Centre (Burgundy, France). The therapeutic follow-up in our centre includes a blood sample analysis to determine 5-FU exposure during the three $1^{\text {st }}$ chemotherapy cycles. Patients eligible for this study were treated with specific digestive 
cancer-treatment regimens by 5 -FU infusion alone or associated with other cytotoxic \pm biotherapy for adjuvant or advanced therapy purposes. The data routinely collected include gender, age, birth date, weight, height, Charlson Comorbidity Index (CCl) (elderly only), primary tumor, type of treatment (metastatic or adjuvant), treatment line, chemotherapy regimen, date of cycle, 5-FU bolus dose, 5-FU infusion dose, 5-FU concentration measured, AUC calculated, proposed dose for the next cycle and toxicities. Individuals were classified into two groups based on age: young group rounded up patients $<75$ years old and elderly included all patients $\geq 75$.

\section{Study design and chemotherapy regimen adjustment}

At cycle $1(\mathrm{C} 1)$, patients received folinic acid $\left(400 \mathrm{mg} / \mathrm{m}^{2}\right)$ by i.v. infusion over $2 \mathrm{~h}$ followed by a 5 -FU bolus $\left(400 \mathrm{mg} / \mathrm{m}^{2}\right.$ ) and immediately after by $46 \mathrm{~h}$ continuous 5 -FU infusion ( 2400 $\mathrm{mg} / \mathrm{m}^{2}$ ) administered via a battery-operated pump. Patients could receive other cytotoxic drugs and/or biotherapy before 5-FU regimen. Area Under the Curve (AUC) of 5-FU infusion was calculated by multiplying the 5-FU steady-state concentration by the infusion duration (46h). At the cycle $2(\mathrm{C} 2)$, the dose of $5-\mathrm{FU}$ infusion was determined according to an algorithm derived from Gamelin's one, targeting AUC range of 18-28 mg.h/L. The same methodology was applied at C2 to ensure correct exposure and perform dose adaptation at the cycle 3 (C3) if necessary. Doses were to remain constant during the subsequent cycles, except in case of severe toxicity. Clinicians were free to individually adapt any other drugs doses included in the protocol.

\section{Blood sampling and plasma concentration determination}

To limit within-day variability of DPD activity (35), blood samples were taken between 8 and 10 a.m. the day following the beginning of 5-FU infusion. Samples were immediately 
centrifuged and plasma kept frozen at $-20^{\circ} \mathrm{C}$ until analysed. Plasma 5-FU concentrations were determined by liquid chromatography. Chloro-uracil was used as internal standard. 5FU was extracted from the plasma with isopropanol-ethyl acetate (15/85 v:v) in the presence of $200 \mathrm{mg}$ ammonium sulfate to precipitate proteins. The organic phase was dried at $50^{\circ} \mathrm{C}$ under nitrogen dioxide and reconstituted with $200 \mu \mathrm{L}$ mobile phase before injection. Mobile phase consisted of methanol/water (5/95 v:v). UV detection was performed at $265 \mathrm{~nm}$. This method was fully validated for routine measurement of 5-FU with a lower limit of quantification of $30 \mu \mathrm{g} / \mathrm{L}$.

\section{Toxicities classification}

All toxicities graded according to the $\mathrm{NCl}$ Common Terminology Criteria for Adverse Events (CTCAE) (Version 4.0) and were clinically or biologically evaluated before each cycle with particular attention to diarrhoea, neutropenia, mucositis and hand-foot syndrome. Severe toxicity was defined as grade 3 or grade 4 toxicity.

\section{Statistical methods}

The distribution of patients' characteristics was expressed as percentages or mean values presented as mean \pm SD (range) or median (range) if deemed appropriate. The statistical analysis was conducted in patients older than 75 years or younger than 75 years. Univariate analyses were performed. Quantitative data were analysed using Student's test or nonparametric Mann-Whitney test for small sample size (effective < 30). Percentages were compared using two proportions comparison test, Pearson's Chi-squared test for multiple samples or Fisher's exact test for small sample size. The level of statistical significance was set at $p=0.05$. Most analyses were performed using SIGMAPLOT ${ }^{\odot}$ software $($ Version 11.0 , SYSTAT Software, Inc). 


\section{Patient characteristics}

160

161

162

163

164

165

166

167

168

169

170

171

172

173

174

175

176

177

A total of 154 patients with gastro-intestinal cancer were enrolled in our study. Thirty-one of them were above 75 years or older and were included in the elderly group, whereas 123 were included in the younger adult group. Demographic data and study treatment details are listed in Table 1.

The most frequent cancer which affects each group was the CRC (74\% in elderly and $56.9 \%$ in younger adult). Pancreas was the $2^{\text {nd }}$ most frequent site $(25.2 \%)$ in young adults, while there was as much pancreatic cancer as stomach or oesophagus cancer (6.5\%) in the elderly. The proportion of patients treated in adjuvant and in metastatic settings was similar in both groups. However, when only FOLFIRINOX regimens were considered, there was significantly more treated patients (38.2\%) in younger adults than in elderly (9.7\%). Overall, elderly patients received $28.2 \%$ less irinotecan-based chemotherapy than younger patients. It should be noted that $67.7 \%$ of elderly were treated as first line therapy.

\section{Interindividual variability in 5-FU pharmacokinetics}

Figure 1 represents plasma 5-FU concentrations as a function of 5-FU-infusion dose (calculated according to BSA) for each patient at C1. No proportionality between dose and concentration was found. A considerable difference in blood concentrations was observed for a same 5-FU dose in both groups. For example, in elderly, steady-state 5-FU concentrations were ranging from $110 \mu \mathrm{g} / \mathrm{L}$ to $706 \mu \mathrm{g} / \mathrm{L}$ for an identical total dose of 4000 mg. Similar conclusions could be drawn from younger patients but this variability seems to be much more substantial among elderly. Consequently, the goal of 5-FU BSA dosing (i.e., bring all patients in the same target exposure) is not reached and those results confirm the 
need to use another dose adjustment method than calculating 5-FU dose according to BSA and more for elderly patients.

To confirm that 75 years old was a valuable cut-off, proportions of patients inside or outside the 5-FU AUC range were compared for 4 age ranges (Table 2). AUC distribution was not significantly different between the three youngest groups $(p=0.920)$. To note, there was no patient over-exposed in the group of 55 years or less. On the contrary, the proportion of patients $\geq 75$ years well-exposed did not reach $30 \%$ (i.e., $24 \%$ less compared with $65-75$ years group $(p=0.039))$. Applying a cut-off value of 70 years would lead to no significant difference in terms of proportion of patient well-exposed between $65-70$ years (50\%) and 70 years or more $(40 \%)$ groups $(p=0.386)$. Same results were observed for under-exposed patients $(36 \%$ vs $42 \%, p=0.583)$ and over-exposed patients $(14 \%$ vs $18 \%, p=0.611)$ respectively. Thus, a cut-off value of 75 years was considered as pertinent.

\section{Impact of 5-FU TDM and individual dose adjustment to reach target AUC}

\section{range}

At C1 (i.e., with dose adapted according to BSA), the mean initial exposure for elderly patients was $21.2 \pm 10.1 \mathrm{mg} . \mathrm{h} / \mathrm{L}$ and $20.2 \pm 6.2 \mathrm{mg} . \mathrm{h} / \mathrm{L}$ for younger adults with a $47 \%$ and $30 \%$ coefficient of variation (\%CV) in each of the groups. Mean doses administered to elderly (4 $239 \pm 418 \mathrm{mg}$ ) were not significantly different from the ones administered to younger adults (4 $234 \pm 536 \mathrm{mg}$ ) ( $p=0.951$ ), which might explain why no difference was found between AUC in the two groups $(p=0.598)$. However, when AUC \%CV are compared between $\mathrm{C} 1$ and $\mathrm{C} 3$ (i.e. after 2 cycles of TDM) an important decrease (- 20\%) is observed for elderly. This decrease is reflected a lesser AUC variability among individuals. 
As shown in Figure 2, at C1, where the initial 5-FU infusion doses were calculated based on BSA, only $29 \%$ of elderly presented an AUC within the therapeutic range, whereas $50 \%$ of younger adults were within this same range $(p=0.049)$. Of the 13 elderly patients who were under-dosed at cycle 1, 11 of them (85\%) had a dose adjustment at cycle 2 with an average increase of $963 \mathrm{mg}(23 \%)$ compared to the mean initial dose of 5-FU. Interestingly, after 5FU PK-guided dosing adjustment, the percentage of elderly patients below the target AUC decreased from 46\% (13 of 28) to 25\% (7 of 28) between cycle 1 and cycle 2 while the percentage of elderly within the therapeutic range significantly increased from $29 \%$ ( 8 of 28 ) at cycle 1 to $64 \%$ (18 of 28 ) at cycle 2 ( $p=0.011$ ). Similarly, the proportion of younger patients who had an AUC within the therapeutic range progressed from $50 \%$ to $68 \%$ between the two $1^{\text {st }}$ cycles $(p=0.008)$. At cycle 2 and 3 , there was no statistically significant difference concerning proportion of under-, well- or over-exposed patients in both groups.

\section{Relation between 5-FU exposure and toxicity}

Main adverse events in the two groups were analysed at C1. All grades diarrhoea, hand-foot syndrome, and neutropenia tend to be more frequent in the younger group as compared to elderly, however differences were not statistically significant. The incidence of severe mucositis (grade $\geq 3$ ) was relatively low in both groups, but elderly tended to be more exposed than younger patients $(7.1 \%$ vs $2.7 \%$ respectively, $p=0.024)$.

At C1, $10 \%$ of elderly below or within AUC range declared severe toxicity compared to $29 \%$ of those above AUC target. The only grade III/IV toxicities, below or within therapeutic AUC range, declared among elderly patients were mucositis. Elderly patients above the AUC range presented mostly neutropenia and diarrhoeas. The incidence of serious toxicities for 
patients below or within AUC range did not differ significantly between the 2 groups ( $p=$ 0.905); as for patients above AUC range $(p=0.683)$.

All cycles combined, lower AUC values were observed for elderly presenting no toxicity or at least non-severe (grade I/II) $(21.3 \pm 7.7 \mathrm{mg} . \mathrm{h} / \mathrm{L})$ compared to those presenting severe toxicity (grade III/IV) (28.2 $\pm 7.7 \mathrm{mg} . \mathrm{h} / \mathrm{L})$ (Figure 3). Conversely, all cycles and grade combined, patients over-dosed presented almost twice as much toxicities than patients under or welldosed $(67.3 \%$ vs $35.8 \%$ respectively, $p<0.0001)$.

\section{Impact of 5-FU PK-guided dosing adjustment to reduce toxicity}

At C1 and C3, lower incidence of grade III/IV toxic effects was observed for both groups (Figure 4). Decrease of severe toxicities was even more important for elderly (15\% vs $5 \%$ respectively). Of note, no grade IV toxicities at cycles 2 and 3 was observed in the elderly group when compared to 1 during C1.

Seven young patients benefited from 5-FU bolus dose reduction between $\mathrm{C} 1$ and $\mathrm{C} 2$, due to grade IV toxicities or hospitalisation during the inter-cycle. Among them, four patients had also a 5-FU infusion reduction, while only 1 of them was over-exposed. Three elderly had bolus dose reduction due to grade III adverse events $(N=2)$ and/or over-exposure $(N=2)$.

The 2 patients who had AUC above target benefited from an infusion dose reduction too. Overall, all cycles combined, 3 out of 5 elderly and 5 out of 13 young patients presented toxicities in spite of the absence of 5-FU bolus dose (mostly grade I/II for the 2 groups) and in the absence of an over-exposure for most of them. 


\section{Relationship between Charlson Comorbidity Index (CCI) and PK or toxicity}

Comorbidity was calculated for all elderly patients; CCI ranged from 5 to 13 , with 28 patients having a $\mathrm{CCl} \geq 6$. All cycles combined, no correlation between comorbidity score and 5-FU AUC value was observed $\left(r^{2}=0.0204\right)$. Similarly, the median of CCI was not statistically different between the no toxicity or at least non-severe group compared to the severe toxicity one $(p=0.057)$.

\section{DISCUSSION}

Considering population aging and the increasing proportion of elderly patients treated for cancer in general and particularly for gastrointestinal cancer, it is important to evaluate the impact of cytotoxic agents, such as 5-FU, in this population. Such studies could have a major impact in the improvement of elderly patient management in current practice. Indeed, aging can alter physiological functions and biological characteristics which could change the pharmacokinetics of drugs, modify the plasma concentrations, and consequently, affect the tolerability and effectiveness of the chemotherapy. Even if, Etienne's PK analysis (36) revealed that age, as model covariate, had a negative impact on 5-FU clearance, other publications founded no significant influence of age on liver DPD activity (37-39). Furthermore, Duffour's paper (40), which compared 5-FU pharmacokinetic parameters between two groups (age $<$ or $\geq 65$ years) receiving LV5FU2 regimen, indicated that mean clearance in elderly patients did not differ from younger people. Because no initial 5fluorouracil dose reduction is recommended for patients with altered renal or hepatic function, elderly patients should be treated as younger patients. However, in current clinical practice, empirical dose reductions or shorter chemotherapy regimens are often prescribed in elderly patients, mainly due to fear of severe toxicity. 
Although 5-FU dosing is traditionally calculated according to BSA, a number of studies have

271

272

been conducted to evaluate an appropriate dose adjustment algorithm and to demonstrate the advantage of 5-FU PK-guided dosing to reduce toxicity and enhance therapeutic outcomes. Nevertheless, those studies mainly concerned young patients ( $<65$ years old) and very few data exist for elderly ones. In our study, we have chosen to divide our population by age range and evaluate 5-FU AUC range for each group to find optimal cut-off value of age. Our data suggest that 75 years as a cut-off is better than the more frequently used 65 or 70 years. Indeed, we demonstrated that 5-FU BSA-dosing in 75 years or more patients is even less suitable than in young people (only $29 \%$ of well-expose with dose adapted according to $\mathrm{BSA}$ ), leading to a non-optimal treatment in this frail population. In this paper, we show that 5-FU PK-guided dosing may help to reduce toxicity from cycle 1 to subsequent cycle in elderly patients, and this, while increasing the dose in under-dosed patients.

At the $1^{\text {st }}$ cycle, mean 5 -FU doses administered to elderly (4 $239 \pm 418 \mathrm{mg}$ ) were not different from those administered to young people (4 $234 \pm 536 \mathrm{mg}$ ). However, a difference in terms of 5-FU combination was observed. Indeed, elderly received nearly $30 \%$ less irinotecan-based chemotherapy (the cornerstone of $1^{\text {st }}$ line metastatic CRC) than younger patients, while $48 \%$ of them received a $1^{\text {st }}$ line metastatic chemotherapy. This observation suggests that oncologists, in our Cancer Centre, tend to favour less aggressive regimens more than 5-FU dose reduction in elderly patients.

As a reminder, for this study, individual doses adjustment was based on systemic exposure measured at the previous cycle. A range of 18-28 mg.h/L, based on Gamelin's algorithm (29), was used as target AUC. Upon BSA-based dosing at cycle 1, only $29 \%$ of older than 75 years group had a 5-FU AUC within the target range while $50 \%$ of young patients were within this 
therapeutic range. This result leads to an important variability in 5-FU steady-state

294 concentrations, ranging, for example, from $110 \mu \mathrm{g} / \mathrm{L}$ to $706 \mu \mathrm{g} / \mathrm{L}$ for an identical total dose of $4000 \mathrm{mg}$ for elderly. In comparison, PK-guided 5-FU dosing performed at cycle 2 resulted in significantly higher proportion of elderly achieving the target AUC (64\%), with, in particular, a considerable average increase of the dose $(963 \mathrm{mg}$ ) among old patients underdosed at C1. Indeed, almost half of elderly (46\%) were under-exposed at cycle 1 versus $25 \%$ at cycle 2. In our study, dose adaptation upon over- or under-exposure was not mandatory; in some situations, for clinical reasons, some practitioners have decided not to follow our recommendations of 5-FU dosing adjustment. For the second cycle, $25 \%$ of elderly underdosed did not had a dose increase as proposed, which could partly explain why still $25 \%$ of elderly patients are below the therapeutic range at cycle 2 . However, this observation is not different for younger patients. In fact, the proportion of under-, over- and well-exposed patients were identical between young and elderly patients at cycle 2 and 3 . The study of Wilhelm et al. (41), which enrolled 33 patients $<65$ years and 42 patients $\geq 65$ years with CRC receiving the weekly regimens of AIO (folinate, 5-FU), FUFOX (oxaliplatin, folinate, 5-FU) or the biweekly regimen of modified FOLFOX-6, resulted in $64 \%$ of all patients under the therapeutic range, $33 \%$ of them well-dosed and $3 \%$ who were over-exposed at the cycle 1. In Saam's paper (42), 5-FU AUC were monitored during 4 cycles in 64 colorectal cancer patients receiving any regimen in which 5-FU was administered over a period of 44-48 hours. If necessary, a 5-FU PK-guided adjustment was performed after receiving the first 5-FU BSAbased dose. The first measurement indicated that $68 \%$ of patients were under-exposed, $13 \%$ were in therapeutic range and $19 \%$ had an AUC over the superior target level. According to our investigations and the results presented in the studies previously referred, we demonstrate that the vast majority of patients is not in the expected therapeutic range after 
receiving standard 5-FU BSA-based dose. The high interindividual variability following dose adaptation testifies of a very limited interest of the 5-FU BSA-based dosing. Upon 5-FU PK-

319 guided dose adjustment in subsequent cycles, a significant decrease of this variability was 320 observed.

Reports concerning tolerance of 5-FU-based chemotherapy in elderly patients are conflicting: some publications describe an increase rates of stomatitis, nausea, diarrhoea,

323 leukopenia, or neutropenia (43-45), whereas no excess toxicity have been observed in others reports $(33,34,46)$. In our investigation, after receiving a standard 5-FU BSA-based dose, the 325 frequency of diarrhoea, hand-foot syndrome, and neutropenia was statistically similar between young and old patients. However, elderly tended to be more susceptible to severe

327 mucositis than younger patients; the use of dental prosthesis and fixed implant, often linked to advanced age, is frequently responsible for inflammation of the oral mucosa $(47,48)$ and could partly explain this higher proportion of elderly who presented serious mouth ulcers compared with young people. Diarrhoea and neutropenia were mostly severe toxicities observed among elderly over-dosed; this observation is not surprising given that numerous

332 publication demonstrate the link between cytotoxic concentrations and the severity of neutropenia or diarrhoea $(49,50)$. Generally, we observed that grade III/IV toxicities were associated with a higher AUC than grade I/II. Conversely, almost twice as much toxicities were observed among patients over-exposed than patients under or well-exposed. As expected, the 5-FU PK-guided dose adjustment reduced the risk of adverse events, particularly severe toxicities. Lower incidence of grade III/IV were observed for the two 338 groups between cycle 1 and 3 and no grade IV toxicity was reported at cycle 2 and 3 among 339 elderly. 
In Sargent's paper (33), a pooled analysis of 3351 patients from 7 randomized phase 3 trials

341

342 was performed. Patients who received 5-FU alone as adjuvant treatment were grouped into 10-year age ranges categories of equal size including a group over 70 years old. Study reported that treatment among elderly had the same benefit/risk ratio as for younger patient groups, with no statistically significant increase in toxicity. However, most of the time, clinical trials exclude elderly or include only highly selected old patients. For elderly patients with good Performance Status (PS) and low Charlson Comorbidity Index (CCI), there is evidence showing both efficacy and acceptable toxicity of chemotherapy (55), but what about the influence of these two parameters on toxicity in older people more frail? In our study, all elderly treated by 5-FU for a gastro-intestinal cancer during the study period were included. Consequently, we believe that our study population is representative of the general elderly population, contrarily to what is observed in a clinical trial. For analyses, PS was not available for all the patients, but we were able to calculate $\mathrm{CCl}$ for elderly; $90 \%$ of them having a $\mathrm{CCl} \geq 6$, which associated with a very important 10 -year mortality rate (56). As Jehn's results (57), in our study using 5-FU, the presence of comorbidity did not confer increased risk of toxicity or superior AUC values. Thus, we may consider that 5-FU PK-dosing can improve the exposition and tolerability of 5-FU in elderly, regardless of clinical condition.

The main limitation of this work is that, at the time of the study, DPD genotyping or phenotyping were not available in our institution. Thus, dose adaptation at cycle 1 based on these criteria was not possible. Nowadays, a pre-therapeutic screening of DPD activity by pharmacogenetics is systematically performed. Patients with no DPD deficiency receive full dose, while the dose is decreased, as early as the first cycle, in agreement with DPYD variants for patients presenting a DPD deficiency. During the following cycles, the dose is adjusted according to AUC and toxicity. 
We demonstrated, throughout this work, the importance of considering interindividual variability of 5-FU exposure. However, efficacy of 5-FU is not only dependent on 5-FU metabolism but also by the use of folinic acid in association which acts as co-activator of the thymidylate synthetase, the main target of 5-FU. Even if folinic acid is associated to a limited degree with clinical outcomes (58), it should be emphasized that its interindividual variability was not considered for this study.

Generally, clinical trials exclude elderly or include highly selected old patients in terms of

372 performance status (PS) and co-morbidity. In our study, all elderly treated by 5-FU for a gastrointestinal cancer during the study period were included. Consequently, despite a small number of patients $(n=31)$, we believe that they represent the general elderly population.

\section{CONCLUSION}

377 Overall, our analysis confirms that BSA-based dosing explains high 5-FU concentration 378 variability among patients. The difficulty to predict 5-FU plasma levels for a given dose 379 frequently led to ineffective concentrations or severe toxicities. PK-guided 5-FU dosing algorithm allowed 5-FU dose adaptation, leading to an improved tolerability while remaining within therapeutic concentration range. This tool, previously described as effective in the general population or young patients, is even more valuable for patients over 75 years old.

\section{Ethics approval}


385 All patients routinely underwent a blood analysis in order to evaluate their 5-FU exposure 386 during the 3 first cycles. Consequently, no informed consent was required. However, data 387 used in this manuscript were recorded in such a manner that subjects could not be 388 identified. Patient confidentiality was maintained and the protocol for data collection and 389 analysis followed guidelines and were approved by our Institutional Review Board.

\section{Availability of data}

391 Data are available upon request to the corresponding author.

392 Conflict of interest

393 The authors declare no conflict of interest.

\section{$394 \quad$ Funding}

395 None

\section{Author contributions}

397 Study conception and design: FG, LBL, AS

398 Acquisition of data: JV, VQ, SM, FG, LBL

399 Analysis and interpretation of data: PM, KM, FG, LBL, AS

400 Drafting of manuscript: PM, AS

401 Critical revision: PM, FG, LBL, AS

402 Final approval: PM, KM, JV, VQ, SM, FG, LBL, AS

403 Acknowledgments

404 We thank Isabel Grégoire for language editing. 
406

407

408

409

410

411

412

413

414

415

416

417

418

419

420

421

422

423

424

425

426

427

428

429

430

431

432

433

434

435

436

437

438

439

440

441

442

443

444

445

446

447

448

449

450

451

452

453

1. Capitain O, Boisdron-Celle M, Poirier AL, Abadie-Lacourtoisie S, Morel A, Gamelin E. The influence of fluorouracil outcome parameters on tolerance and efficacy in patients with advanced colorectal cancer. The pharmacogenomics journal. 2008;8(4):256-67.

2. Qu JL, Li X, Qu XJ, Zhu ZT, Zhou LZ, Teng YE, et al. Optimal duration of fluorouracil-based adjuvant chemotherapy for patients with resectable gastric cancer. PloS one. 2013;8(12):e83196.

3. Lokich JJ. Optimal schedule for 5-fluorouracil chemotherapy. Intermittent bolus or continuous infusion? American journal of clinical oncology. 1985;8(5):445-8.

4. Lokich JJ, Ahlgren JD, Gullo JJ, Philips JA, Fryer JG. A prospective randomized comparison of continuous infusion fluorouracil with a conventional bolus schedule in metastatic colorectal carcinoma: a Mid-Atlantic Oncology Program Study. Journal of clinical oncology : official journal of the American Society of Clinical Oncology. 1989;7(4):425-32.

5. Rougier P, Paillot B, LaPlanche A, Morvan F, Seitz JF, Rekacewicz C, et al. 5-Fluorouracil (5-FU) continuous intravenous infusion compared with bolus administration. Final results of a randomised trial in metastatic colorectal cancer. European journal of cancer. 1997;33(11):1789-93.

6. Meta-Analysis Group In C, Levy E, Piedbois P, Buyse M, Pignon JP, Rougier P, et al. Toxicity of fluorouracil in patients with advanced colorectal cancer: effect of administration schedule and prognostic factors. Journal of clinical oncology : official journal of the American Society of Clinical Oncology. 1998;16(11):3537-41.

7. Tsalic $M$, Bar-Sela $G$, Beny A, Visel B, Haim N. Severe toxicity related to the 5fluorouracil/leucovorin combination (the Mayo Clinic regimen): a prospective study in colorectal cancer patients. American journal of clinical oncology. 2003;26(1):103-6.

8. Meulendijks D, Henricks LM, Sonke GS, Deenen MJ, Froehlich TK, Amstutz U, et al. Clinical relevance of DPYD variants c.1679T>G, c.1236G >A/HapB3, and c.1601G >A as predictors of severe fluoropyrimidine-associated toxicity: a systematic review and meta-analysis of individual patient data. The Lancet Oncology. 2015;16(16):1639-50.

9. van Kuilenburg $A B$. Dihydropyrimidine dehydrogenase and the efficacy and toxicity of 5fluorouracil. European journal of cancer. 2004;40(7):939-50.

10. Liu XQ, Zhuang $M$, Wang $Z$, Huber RM. Correlation between dihydropyrimidine dehydrogenase and efficacy and toxicity of fluoropyrimidine drugs. European review for medical and pharmacological sciences. 2014;18(18):2772-6.

11. Amstutz $U$, Froehlich TK, Largiader CR. Dihydropyrimidine dehydrogenase gene as a major predictor of severe 5-fluorouracil toxicity. Pharmacogenomics. 2011;12(9):1321-36.

12. Matsusaka S, Lenz HJ. Pharmacogenomics of fluorouracil -based chemotherapy toxicity. Expert opinion on drug metabolism \& toxicology. 2015;11(5):811-21.

13. Bocci G, Barbara C, Vannozzi F, Di Paolo A, Melosi A, Barsanti G, et al. A pharmacokineticbased test to prevent severe 5-fluorouracil toxicity. Clinical pharmacology and therapeutics. 2006;80(4):384-95.

14. Boisdron-Celle M, Remaud G, Traore S, Poirier AL, Gamelin L, Morel A, et al. 5-Fluorouracilrelated severe toxicity: a comparison of different methods for the pretherapeutic detection of dihydropyrimidine dehydrogenase deficiency. Cancer letters. 2007;249(2):271-82.

15. Saif MW, Ezzeldin H, Vance K, Sellers S, Diasio RB. DPYD*2A mutation: the most common mutation associated with DPD deficiency. Cancer chemotherapy and pharmacology. 2007;60(4):5037.

16. Saif MW, Syrigos K, Mehra R, Mattison LK, Diasio RB. Dihydropyrimidine Dehydrogenase Deficiency (Dpd) in Gi Malignancies: Experience of 4-Years. Pakistan journal of medical sciences. 2007;23(6):832-9.

17. Ezzeldin $H$, Johnson MR, Okamoto $Y$, Diasio R. Denaturing high performance liquid chromatography analysis of the DPYD gene in patients with lethal 5-fluorouracil toxicity. Clinical 
cancer research : an official journal of the American Association for Cancer Research. 2003;9(8):30218.

18. Cai X, Fang JM, Xue P, Song WF, Hu J, Gu HL, et al. The role of IVS14+1 G > A genotype detection in the dihydropyrimidine dehydrogenase gene and pharmacokinetic monitoring of 5fluorouracil in the individualized adjustment of 5-fluorouracil for patients with local advanced and metastatic colorectal cancer: a preliminary report. European review for medical and pharmacological sciences. 2014;18(8):1247-58.

19. Schwab M, Zanger UM, Marx C, Schaeffeler E, Klein K, Dippon J, et al. Role of genetic and nongenetic factors for fluorouracil treatment-related severe toxicity: a prospective clinical trial by the German 5-FU Toxicity Study Group. Journal of clinical oncology : official journal of the American Society of Clinical Oncology. 2008;26(13):2131-8.

20. van Kuilenburg AB, Maring JG, Schalhorn A, Terborg C, Schmalenberg H, Behnke D, et al. Pharmacokinetics of 5-fluorouracil in patients heterozygous for the IVS14+1G > A mutation in the dihydropyrimidine dehydrogenase gene. Nucleosides, nucleotides \& nucleic acids. 2008;27(6):692-8. 21. Ciccolini J, Gross E, Dahan L, Lacarelle B, Mercier C. Routine dihydropyrimidine dehydrogenase testing for anticipating 5-fluorouracil-related severe toxicities: hype or hope? Clinical colorectal cancer. 2010;9(4):224-8.

22. van Kuilenburg AB, Hausler P, Schalhorn A, Tanck MW, Proost JH, Terborg C, et al. Evaluation of 5-fluorouracil pharmacokinetics in cancer patients with a c.1905+1G>A mutation in DPYD by means of a Bayesian limited sampling strategy. Clinical pharmacokinetics. 2012;51(3):163-74.

23. Lee JJ, Beumer JH, Chu E. Therapeutic drug monitoring of 5-fluorouracil. Cancer chemotherapy and pharmacology. 2016;78(3):447-64.

24. Gamelin E, Boisdron-Celle M, Guerin-Meyer V, Delva R, Lortholary A, Genevieve F, et al. Correlation between uracil and dihydrouracil plasma ratio, fluorouracil (5-FU) pharmacokinetic parameters, and tolerance in patients with advanced colorectal cancer: A potential interest for predicting 5-FU toxicity and determining optimal 5-FU dosage. Journal of clinical oncology : official journal of the American Society of Clinical Oncology. 1999;17(4):1105.

25. Paci A, Veal G, Bardin C, Leveque D, Widmer N, Beijnen J, et al. Review of therapeutic drug monitoring of anticancer drugs part 1--cytotoxics. European journal of cancer. 2014;50(12):2010-9.

26. Bardin C, Veal G, Paci A, Chatelut E, Astier A, Leveque D, et al. Therapeutic drug monitoring in cancer--are we missing a trick? European journal of cancer. 2014;50(12):2005-9.

27. Fety R, Rolland F, Barberi-Heyob M, Hardouin A, Campion L, Conroy T, et al. Clinical impact of pharmacokinetically-guided dose adaptation of 5-fluorouracil: results from a multicentric randomized trial in patients with locally advanced head and neck carcinomas. Clinical cancer research : an official journal of the American Association for Cancer Research. 1998;4(9):2039-45.

28. Ychou M, Duffour J, Kramar A, Debrigode C, Gourgou S, Bressolle F, et al. Individual 5-FU dose adaptation in metastatic colorectal cancer: results of a phase II study using a bimonthly pharmacokinetically intensified LV5FU2 regimen. Cancer chemotherapy and pharmacology. 2003;52(4):282-90.

29. Gamelin E, Delva R, Jacob J, Merrouche Y, Raoul JL, Pezet D, et al. Individual fluorouracil dose adjustment based on pharmacokinetic follow-up compared with conventional dosage: results of a multicenter randomized trial of patients with metastatic colorectal cancer. Journal of clinical oncology : official journal of the American Society of Clinical Oncology. 2008;26(13):2099-105.

30. Morawska K, Goirand F, Marceau L, Devaux M, Cueff A, Bertaut A, et al. 5-FU therapeutic drug monitoring as a valuable option to reduce toxicity in patients with gastrointestinal cancer. Oncotarget. 2018;9(14):11559-71.

31. Kaldate RR, Haregewoin A, Grier CE, Hamilton SA, McLeod HL. Modeling the 5-fluorouracil area under the curve versus dose relationship to develop a pharmacokinetic dosing algorithm for colorectal cancer patients receiving FOLFOX6. The oncologist. 2012;17(3):296-302.

32. Braiteh FS, Salamone SJ, Li Y, Courtney JB, Duda M, Diamond S, et al. Pharmacokinetic (PK)guided optimization of 5-fluorouracil (5FU) exposure in colorectal cancer (CRC) patients: U.S.-based clinical practices experience. Journal of Clinical Oncology. 2014;32(15_suppl):3574-. 
33. Sargent DJ, Goldberg RM, Jacobson SD, Macdonald JS, Labianca R, Haller DG, et al. A pooled analysis of adjuvant chemotherapy for resected colon cancer in elderly patients. The New England journal of medicine. 2001;345(15):1091-7.

34. Sundararajan V, Mitra N, Jacobson JS, Grann VR, Heitjan DF, Neugut Al. Survival associated with 5 -fluorouracil-based adjuvant chemotherapy among elderly patients with node-positive colon cancer. Annals of internal medicine. 2002;136(5):349-57.

35. Jacobs BA, Deenen MJ, Pluim D, van Hasselt JG, Krahenbuhl MD, van Geel RM, et al. Pronounced between-subject and circadian variability in thymidylate synthase and dihydropyrimidine dehydrogenase enzyme activity in human volunteers. British journal of clinical pharmacology. 2016;82(3):706-16.

36. Etienne MC, Chatelut E, Pivot X, Lavit M, Pujol A, Canal P, et al. Co-variables influencing 5fluorouracil clearance during continuous venous infusion. A NONMEM analysis. European journal of cancer. 1998;34(1):92-7.

37. Lu Z, Zhang R, Diasio RB. Population characteristics of hepatic dihydropyrimidine dehydrogenase activity, a key metabolic enzyme in 5-fluorouracil chemotherapy. Clinical pharmacology and therapeutics. 1995;58(5):512-22.

38. Ezzeldin H, Diasio R. Dihydropyrimidine dehydrogenase deficiency, a pharmacogenetic syndrome associated with potentially life-threatening toxicity following 5-fluorouracil administration. Clinical colorectal cancer. 2004;4(3):181-9.

39. Niwa T, Shiraga T, Ohno $\mathrm{Y}$, Kagayama A. Interindividual variability in 5-Fluorouracil metabolism and procainamide $\mathrm{N}$-acetylation in human liver cytosol. Biological \& pharmaceutical bulletin. 2005;28(6):1071-4.

40. Duffour J, Roca L, Bressolle F, Abderrahim AG, Poujol S, Pinguet F, et al. Clinical impact of intesified 5-Fluorouracil-based chemotherapy using a prospective pharmacokinetically-guided dosing approach: comparative study in elderly and non-elderly patients with metastatic colorectal cancer. Journal of chemotherapy. 2010;22(3):179-85.

41. Wilhelm M, Mueller L, Miller MC, Link K, Holdenrieder S, Bertsch T, et al. Prospective, Multicenter Study of 5-Fluorouracil Therapeutic Drug Monitoring in Metastatic Colorectal Cancer Treated in Routine Clinical Practice. Clinical colorectal cancer. 2016;15(4):381-8.

42. Saam J, Critchfield GC, Hamilton SA, Roa BB, Wenstrup RJ, Kaldate RR. Body surface areabased dosing of 5-fluoruracil results in extensive interindividual variability in 5-fluorouracil exposure in colorectal cancer patients on FOLFOX regimens. Clinical colorectal cancer. 2011;10(3):203-6.

43. Stein BN, Petrelli NJ, Douglass HO, Driscoll DL, Arcangeli G, Meropol NJ. Age and sex are independent predictors of 5 -fluorouracil toxicity. Analysis of a large scale phase III trial. Cancer. 1995;75(1):11-7.

44. Zalcberg J, Kerr D, Seymour L, Palmer M. Haematological and non-haematological toxicity after 5-fluorouracil and leucovorin in patients with advanced colorectal cancer is significantly associated with gender, increasing age and cycle number. Tomudex International Study Group. European journal of cancer. 1998;34(12):1871-5.

45. Popescu RA, Norman A, Ross PJ, Parikh B, Cunningham D. Adjuvant or palliative chemotherapy for colorectal cancer in patients 70 years or older. Journal of clinical oncology : official journal of the American Society of Clinical Oncology. 1999;17(8):2412-8.

46. Chiara S, Nobile MT, Vincenti M, Lionetto R, Gozza A, Barzacchi MC, et al. Advanced colorectal cancer in the elderly: results of consecutive trials with 5-fluorouracil-based chemotherapy. Cancer chemotherapy and pharmacology. 1998;42(4):336-40.

47. Charyeva O, Altynbekov K, Zhartybaev R, Sabdanaliev A. Long-term dental implant success and survival--a clinical study after an observation period up to 6 years. Swedish dental journal. 2012;36(1):1-6.

48. Kowar J, Eriksson A, Jemt T. Fixed implant-supported prostheses in elderly patients: a 5-year retrospective comparison between partially and completely edentulous patients aged 80 years or older at implant surgery. Clinical implant dentistry and related research. 2013;15(1):37-46. 
49. Chiang NJ, Chao TY, Hsieh RK, Wang CH, Wang YW, Yeh CG, et al. A phase I dose-escalation study of PEP02 (irinotecan liposome injection) in combination with 5-fluorouracil and leucovorin in advanced solid tumors. BMC cancer. 2016;16(1):907.

50. Bruera G, Massacese S, Galvano A, Mas AD, Guadagni S, Calvisi G, et al. Dose-finding study of intensive weekly alternating schedule of docetaxel, 5-fluorouracil, and oxaliplatin, FD/FOx regimen, in metastatic gastric cancer. Oncotarget. 2018;9(29):20339-50.

51. Gamelin E, Boisdron-Celle M. Dose monitoring of 5-fluorouracil in patients with colorectal or head and neck cancer--status of the art. Critical reviews in oncology/hematology. 1999;30(1):71-9.

52. Poon MA, O'Connell MJ, Wieand HS, Krook JE, Gerstner JB, Tschetter LK, et al. Biochemical modulation of fluorouracil with leucovorin: confirmatory evidence of improved therapeutic efficacy in advanced colorectal cancer. Journal of clinical oncology : official journal of the American Society of Clinical Oncology. 1991;9(11):1967-72.

53. Chau I, Norman AR, Cunningham D, Tait D, Ross PJ, Iveson T, et al. A randomised comparison between 6 months of bolus fluorouracil/leucovorin and 12 weeks of protracted venous infusion fluorouracil as adjuvant treatment in colorectal cancer. Annals of oncology : official journal of the European Society for Medical Oncology. 2005;16(4):549-57.

54. Milano G, Roman P, Khater R, Frenay M, Renee N, Namer M. Dose versus pharmacokinetics for predicting tolerance to 5-day continuous infusion of 5-FU. International journal of cancer. 1988;41(4):537-41.

55. Goldberg RM, Tabah-Fisch I, Bleiberg H, de Gramont A, Tournigand C, Andre T, et al. Pooled analysis of safety and efficacy of oxaliplatin plus fluorouracil/leucovorin administered bimonthly in elderly patients with colorectal cancer. Journal of clinical oncology : official journal of the American Society of Clinical Oncology. 2006;24(25):4085-91.

56. Charlson ME, Pompei P, Ales KL, Mackenzie CR. A new method of classifying prognostic comorbidity in longitudinal studies: development and validation. Journal of chronic diseases. 1987;40(5):373-83.

57. Jehn CF, Boning L, Kroning H, Pezzutto A, Luftner D. Influence of comorbidity, age and performance status on treatment efficacy and safety of cetuximab plus irinotecan in irinotecanrefractory elderly patients with metastatic colorectal cancer. European journal of cancer. 2014;50(7):1269-75.

58. Ulrich CM, Rankin C, Toriola AT, Makar KW, Altug-Teber O, Benedetti JK, et al. Polymorphisms in folate-metabolizing enzymes and response to 5-fluorouracil among patients with stage II or III rectal cancer (INT-0144; SWOG 9304). Cancer. 2014;120(21):3329-37.

\section{FIGURE LEGENDS}

Figure 1 - Relationship between 5-FU plasma concentration and 5-FU continuous infusion dose at

cycle 1 in elderly and young patients.

Figure 2 - Percentage of patients with 5-FU AUC values below, within or above the therapeutic range at $\mathrm{C} 1$ and $\mathrm{C} 2$

Figure 3 - Distribution of elderly patients presenting no toxicity or at least non-severe compared to those presenting severe toxicity according to AUC values 
598 Figure 4 - Percentage of elderly and young patients developing severe adverse events at C1 and C3 
600 Table 1 - Initial patients characteristics and treatment regimens (NS : non significant)

\begin{tabular}{|c|c|c|c|}
\hline VARIABLE & $\begin{array}{l}\text { YOUNG } \\
(n=123)\end{array}$ & $\operatorname{ELDERL} Y(n=31)$ & $\begin{array}{c}\text { P. } \\
\text { VALUE }\end{array}$ \\
\hline \multicolumn{4}{|l|}{ GENDER, $n(\%)$} \\
\hline Male & $69(56.1)$ & $20(64.5)$ & NS \\
\hline Female & $54(43.9)$ & $11(35.5)$ & NS \\
\hline AGE, years, median (range) & $64(27-74)$ & $79(75-87)$ & $<0.001$ \\
\hline WEIGHT, kg, mean $\pm S D$ (range) & $69.5 \pm 15.1(35-115)$ & $70.9 \pm 13.3(47-109)$ & NS \\
\hline HEIGHT, cm, mean $\pm S D$ (range) & $168.9 \pm 8.4(150-186)$ & $166.4 \pm 8.2(150-182)$ & NS \\
\hline $\begin{array}{l}\text { CHARLSON COMORBODITY } \\
\text { INDEX, median (range) } \\
\text { LOCATION OF CANCER, } n(\%)\end{array}$ & / & $10(5-13)$ & / \\
\hline Colorectal & $70(56.9)$ & $23(74.0)$ & NS \\
\hline Pancreas & $31(25.2)$ & $2(6.5)$ & 0.026 \\
\hline Esophagus & $9(7.3)$ & $2(6.5)$ & NS \\
\hline Stomach & $8(6.5)$ & $2(6.5)$ & NS \\
\hline Others & $5(4.1)$ & $2(6.5)$ & NS \\
\hline \multicolumn{3}{|l|}{ TYPE OF CHEMOTHERAPY, } & \\
\hline Metastatic & $105(85.4)$ & $23(74.2)$ & NS \\
\hline \multicolumn{4}{|l|}{$\begin{array}{l}\text { PROTOCOL OF } \\
\text { CHEMOTHERAPY, } n(\%)\end{array}$} \\
\hline Simplified Folfox-6 & $44(35.8)$ & $17(54.8)$ & NS \\
\hline Folfirinox & $47(38.2)$ & $3(9.7)$ & 0.002 \\
\hline Folfiri & $22(17.9)$ & $6(19.4)$ & NS \\
\hline Lv5fu2 & $4(3.3)$ & 4 (12.9) & NS \\
\hline Folfiri-3 & $6(4.8)$ & $1(3.2)$ & NS \\
\hline \multicolumn{4}{|l|}{ BIOTHERAPY, $n(\%)$} \\
\hline Yes & $59(48.0)$ & $15(48.4)$ & NS \\
\hline No & $64(52.0)$ & $16(51.6)$ & NS \\
\hline \multicolumn{4}{|l|}{ LINE OF TREATMENT, $n(\%)$} \\
\hline 1st Line & $58(47.2)$ & $21(67.7)$ & 0.043 \\
\hline 2nd Line & $39(31.7)$ & $6(19.4)$ & NS \\
\hline 3rd Line or More & $26(21.1)$ & 4 (12.9) & NS \\
\hline
\end{tabular}

601 
603 Table 2 - Percentage of patients with 5-FU AUC values below, within and above the therapeutic range 604 by age groups

\begin{tabular}{c|cccc}
\multicolumn{1}{|c}{ AUC } & $<55$ & $55-65$ & $65-75$ & $\geq 75$ \\
RANGE & YR & YR & YR & YR \\
\hline Below (\%) & 53 & 39 & 36 & 46 \\
Within (\%) & 47 & 51 & 53 & 29 \\
Above (\%) & 0 & 10 & 11 & 25
\end{tabular}

605 


\section{Figure 1}

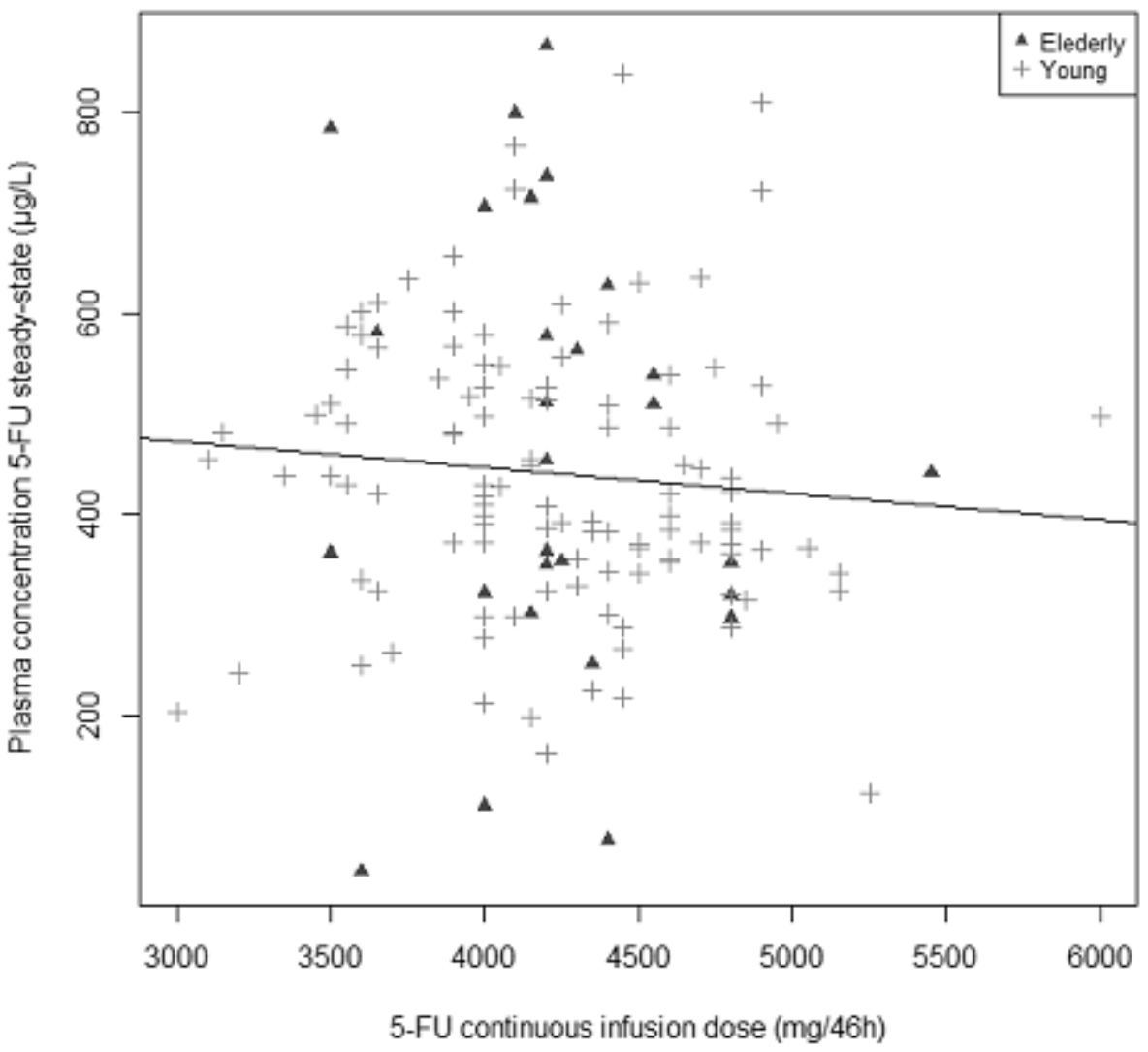




\section{Figure 3}

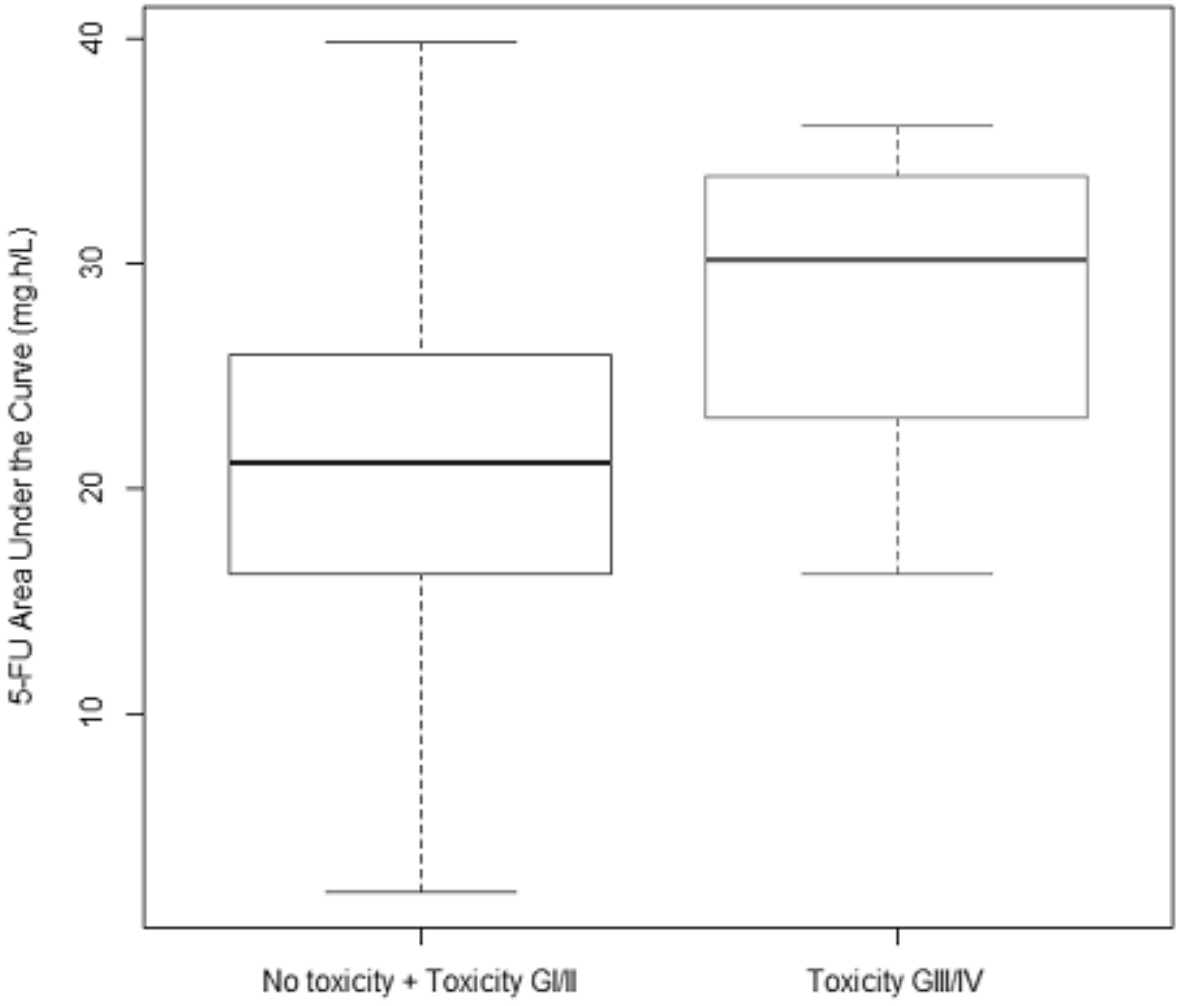


